\title{
Study the cases of rupture uterus in a tertiary care teaching hospital, Jharkhand, India and its maternal and perinatal outcome
}

\author{
Rameshwari Beck¹, Shashi Dinkar Minj²*, Sarita Tirkey ${ }^{3}$, Ajit Kumar ${ }^{3}$, Sukanta Sen ${ }^{4}$
}

\begin{abstract}
${ }^{1}$ Department of Obstetrics and Gynecology, ${ }^{2}$ Department of Anaesthesiology, ICARE Institute of Medical Sciences and Research, Haldia, West Bengal, India

${ }^{3}$ Department of Obstetrics and Gynecology, Rajendra Institute of Medical Sciences, Ranchi, Jharkhand, India

${ }^{4}$ Department of Pharmacology, ICARE Institute of Medical Sciences and Research, Haldia, West Bengal, India
\end{abstract}

Received: 17 December 2017

Accepted: 20 January 2018

\section{*Correspondence:}

Dr. Shashi Dinkar Minj,

E-mail:drsdinkar@gmail.com

Copyright: (c) the author(s), publisher and licensee Medip Academy. This is an open-access article distributed under the terms of the Creative Commons Attribution Non-Commercial License, which permits unrestricted non-commercial use, distribution, and reproduction in any medium, provided the original work is properly cited.

\section{ABSTRACT}

Background: Rupture of a pregnant uterus is a serious obstetric emergency and a common cause of maternal death. Study was done to evaluate the incidence, risk factors, management, maternal and fetal outcome of rupture uterus at RIMS.

Methods: The present study was carried out in 80 cases of rupture uterus admitted in labour room in the department of Obstetrics and Gynaecology, RIMS, Ranchi, India from March 2014 to September 2015.

Results: It was observed that the incidence rate of $0.763 \%$. About $53.75 \%$ of ruptures of uterus were noted after 38 weeks of pregnancy. The cause of rupture uterus during labour in most of the cases was spontaneous (49.34\%). scar rupture was the next frequent cause $(45.33 \%)$ and traumatic rupture were $5.33 \%$. Malpresentation and malposition contributed the most important aetiological factors causing spontaneous rupture during labour (43.24\%). Hysterectomy was performed in $53.75 \%$ (subtotal, 32 cases i.e. $40 \%$ and total, 11 cases i.e. $13.75 \%$ ).

Conclusions: Rupture uterus is a serious and life threatening complication for both mother and the fetus. The leading cause of uterine rupture was found to be neglected and obstructed labor due to mismanagement by local untrained birth attendants. Timely recognition and referral to higher centers can reduce the maternal and fetal morbidity and mortality due to uterine rupture. Education and proper care especially of high risk patients like previous caesarean by competent personnel, proper use of oxytocin and early referral may help to reduce the incidence of rupture uterus.

Keywords: Caesarean section, Maternal outcome, Pregnancy, Perinatal outcome, Rupture uterus

\section{INTRODUCTION}

Rupture of a pregnant uterus is a serious obstetric emergency and a common cause of maternal death. The incidence of uterine rupture varies appreciably among countries. While literature reports that in the developed world the frequency of ruptured uterus has dropped significantly. ${ }^{1}$ It is still a major public health problem in developing countries accounting for $5-18 \%$ of all maternal deaths and a corresponding prenatal mortality rate of $30-95 \%$ in different countries Caesarean section using a safer low transverse incision later becomes quite common. Vaginal delivery after caesarean section has become an integral part of modern obstetrics. This procedure may be viewed as a simple and routine method of delivery. ${ }^{2}$ However, experience has shown that vaginal delivery is not risk free, and uterine rupture has been increasingly recognized as one of the complications that obstetricians should be ready to manage. ${ }^{3}$

In high-income countries ruptured uterus occurs as an occasional obstetric mishap frequently following 
complications of oxytocin induction/ augmentation, trial of prior uterine scar or abdominal trauma such as car accident. In developing countries several underlying factors like poverty, traditional practices, high parity, lack of antenatal care, unsupervised deliveries, poor supply of medical equipments and consumables, and dwindling health care funding have to be taken care of. ${ }^{4}$ Rupture of the uterus may be complete or incomplete depending on whether it opens into the peritoneal cavity or not. It is complete if it communicates with the peritoneal cavity directly and incomplete if it is separated from the peritoneal cavity by the visceral peritoneum and therefore the fetus is not extruded into the abdominal cavity. ${ }^{5}$

Maternal consequences are related to whether there is rupture of an intact uterus or a prior uterine scar. Scar separation following a trial of scar is associated with a lower risk of maternal death compared to spontaneous rupture of an unscarred uterus. ${ }^{6}$ Spontaneous rupture of unscarred uterus is associated with higher maternal case fatality rate compared to rupture of a previously scared uterus and it can be as high as 40 to $50 \% .^{7}$ The risk of maternal death due to uterine rupture is $0-1 \%$ in high income countries, but in low income countries it ranges between $5-10 \%{ }^{8}$ Fetal morbidity invariably occurs because of catastrophic hemorrhage leading to fetal anoxia. With rupture and expulsion of the fetus into the peritoneal cavity the chances of fetal survival are minimal. If the fetus is alive at the time of rupture, the only chance of continued survival is afforded by immediate diagnosis and delivery by laparatomy. Case fatality rate in rupture uterus may be reduced by early diagnosis, urgent resuscitation and laparatomy. Any form of delay increases the chances of dying from severe hemorrhage. ${ }^{9}$

Uterine rupture usually occurs during the course of labour but in some cases uterine rupture can occur during pregnancy without labour, typically this occurs in cases of a uterine scar from classical caesarean section, placenta percreta, invasive mole, choriocarcinoma and cornual pregnancy. Rupture that occurs during labour is much more dangerous than that occurring remote from term/labour because infection is almost inevitable, and shock is usually greater. ${ }^{10}$ The time available for successful intervention after frank uterine rupture and before the onset of major fetal morbidity is very short. Therefore, once the diagnosis of uterine rupture is considered, all available resources must be quickly and effectively mobilized to successfully institute timely surgical treatment that results in favourable outcomes for both the newborn and mother. ${ }^{11}$ The most critical aspects of treatment in the case of uterine rupture are establishing a timely diagnosis and minimizing the time from the onset of signs and symptoms until the start of definitive surgical therapy. Once a diagnosis of uterine rupture is established, immediate stabilization of the mother and the delivery of the fetus are imperative. After the fetus is delivered, the type of surgical treatment for the mother will depend on the type of uterine rupture, extent of uterine rupture, degree of haemorrhage, general condition of the mother and mother's desire for future childbearing. ${ }^{12}$

Other factors that may determine the type of surgical intervention includes urgency, patient's general condition as well as surgeons experience. Conservative surgical management involving uterine repair should be reserved for women who have low transverse uterine rupture, no extension of the tear to the broad ligament, cervix, or paracolpos, previous LSCS scar dehiscence, easily controllable uterine haemorrhage, good general condition, desire for future childbearing and no clinical or laboratory evidence of an evolving coagulopathy. Hysterectomy should be considered the treatment of choice when intractable uterine bleeding occurs or when the uterine rupture sites are multiple, longitudinal or low lying, bruised and contaminated. ${ }^{13}$ Ruptured uterus is in most cases a result of neglected obstructed labour and it is associated with a number of long term maternal complications which in some way affect the quality of life of the affected women if at all she survives the acute phase of the condition. These include vesico-vaginal fistula, recto-vaginal fistula, anaemia, sepsis and psychological trauma. ${ }^{14}$

Objective of present study were to study the incidence of uterine rupture at RIMS, to evaluate risk factors, management, maternal and fetal outcome of rupture uterus and to evaluate the methods to reduce maternal mortality, morbidity and perinatal outcome.

\section{METHODS}

The present study included all cases of ruptured uterus, who was either referred to RIMS after development of complication or develop this in RIMS labour room or shows symptoms of rupture with history of previous caesarean section. The cases were selected from labour room of Department of Obstetrics and Gynecology, RIMS, from March 2014 to September 2015. Institutional ethics approval and individual informed written consent was taken before enrolling study participants.

If patient came as emergency case the following points were noted: pain abdomen with its duration, history of referral, history of administration of medication, any instrumentation, I.V. fluid administration, history of trauma, rupture of membrane with its duration, cessation of labour pain with its duration, any febrile episode, fetal movement, any vaginal discharge and vaginal bleeding. Surgical history e. g. D and E, D and C, MROP, hysteroscopy, hystorotomy, myomectomy and previous LSCS was also noted.

\section{Per vaginal examination}

Condition of the cervix-thin and soft or thick hanging, taking up of the cervix, dilatation of the cervical OS, membrane-present/absent, station of presenting, position 
of presenting part, formation of caput, moulding and any foul smelling discharge, bleeding were also noted.

\section{Surgical management}

Subtotal hysterectomy, total abdominal hysterectomy, uterine repair, uterine repair and bilateral tubectomy, repair of other organs if involved and surgical management of broad ligament hematoma and other hematoma also noted.

\section{Operative findings}

Fetus-in peritoneal cavity and partially extruded was also noted.

\section{RESULTS}

The present observations were made on 80 cases of rupture uterus admitted in the department of obstetrics and gynaecology in RIMS Ranchi from March 2014 to September 2015. Total number of deliveries during that period was 10474 . In the above study we observed 80 cases of rupture uterus so the incidence rate of $0.763 \%$. It is evident from the present observation that the incidence of rupture uterus was more $(97.5 \%)$ in cases who had no previous antenatal check up at all. Incidence of rupture uterus was negligible $(2.5 \%)$ in cases who had antenatal check up even in its minimum capacity. The above table shows that the incidence of rupture uterus was more $(92.5 \%)$ in rural population than urban $(7.5 \%)$.

Table 1: Age distribution of cases of rupture uterus.

\begin{tabular}{|c|c|c|c|c|c|}
\hline Age (Year) & $\begin{array}{l}15- \\
20\end{array}$ & $\begin{array}{l}21- \\
25\end{array}$ & $\begin{array}{l}26- \\
30\end{array}$ & $\begin{array}{l}31- \\
35\end{array}$ & $\begin{array}{l}36 \\
\text { above }\end{array}$ \\
\hline $\begin{array}{l}\text { Total no of } \\
\text { cases }\end{array}$ & 4 & 34 & 30 & 10 & 2 \\
\hline $\begin{array}{l}\text { Percentage } \\
\%\end{array}$ & 5 & 42.5 & 37.5 & 12.5 & 2.5 \\
\hline
\end{tabular}

It has been observed that majority $(42.5 \%)$ of the patients were in the age group of 21 to 25 years (Table 1 ).

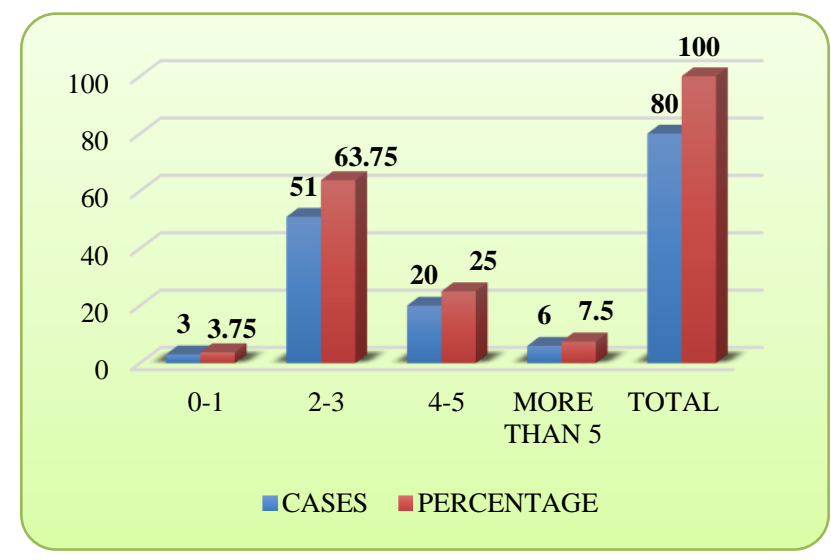

Figure 1: Distribution of cases according to parity.
It is observed from the above table that the most of the cases of the rupture uterus were para 2 to para 3 (Figure 1).

Table 2: Distribution of case according to period of gestation.

\begin{tabular}{|lll|}
$\begin{array}{l}\text { Period of gestation } \\
\text { (weeks) }\end{array}$ & $\begin{array}{l}\text { No. of cases of } \\
\text { rupture uterus }\end{array}$ & Percentage \\
\hline 16 & 1 & 1.25 \\
\hline $30-34$ & 4 & 5.00 \\
\hline $35-37$ & 32 & 40.00 \\
\hline 38 onwards & 43 & 53.75 \\
\hline Total & 80 & 100 \\
\hline
\end{tabular}

The Table 2 shows high incidence of rupture uterus during 38 or more weeks of pregnancy.

Table 3: Causes of rupture uterus during labour.

\begin{tabular}{|lll|}
\hline $\begin{array}{l}\text { Causes of rupture } \\
\text { uterus in labour }\end{array}$ & No. of cases & Percentage \\
\hline Spontaneous & 37 & 49.34 \\
\hline Scar Rupture & 34 & 45.33 \\
\hline Traumatic & 4 & 5.33 \\
\hline Total & 75 & 100 \\
\hline
\end{tabular}

It is evident from the Table 3 that spontaneous rupture was the commonest type of rupture during labour incidence being $(49.34 \%)$. Spontaneous rupture was the next frequent cause (Table 3 ).

Table 4: Causes of spontaneous rupture during labour.

\begin{tabular}{|lll|}
\hline $\begin{array}{l}\text { Causes of } \\
\text { spontaneous rupture }\end{array}$ & $\begin{array}{l}\text { No. of cases } \\
\text { of rupture } \\
\text { uterus }\end{array}$ & Percentage \\
\hline $\begin{array}{l}\text { Malpresentation and } \\
\text { Malposition }\end{array}$ & 16 & 43.24 \\
\hline $\begin{array}{l}\text { Shoulder } \\
\text { Compound }\end{array}$ & 2 & 5.41 \\
\hline Breech & 3 & 2.70 \\
\hline Occipitoposterior & 8 & 8.11 \\
\hline $\begin{array}{l}\text { Grand multiparity with } \\
\text { shoulder presentation }\end{array}$ & 1 & 21.62 \\
\hline $\begin{array}{l}\text { Grand multiparity with } \\
\text { compound presentation }\end{array}$ & 1 & 2.70 \\
\hline Contracted Pelvis & 8 & 2.70 \\
\hline Hydrocephalous & 2 & 21.62 \\
\hline $\begin{array}{l}\text { Manipulation by } \\
\text { Untrained Dais }\end{array}$ & 11 & 5.41 \\
\hline Total & 37 & 29.73 \\
\hline
\end{tabular}

From the above Table 4, it is apparent that the spontaneous rupture was maximum with malpresentation and malposition (43.24\%). This was followed by untrained dais $(29.73 \%)$. 
Table 5: Type of scar rupture during labour.

\begin{tabular}{|c|c|c|}
\hline $\begin{array}{l}\text { Type of caesarean } \\
\text { section scar }\end{array}$ & $\begin{array}{l}\text { No of cases of } \\
\text { rupture uterus }\end{array}$ & Percentage \\
\hline $\begin{array}{l}\text { Previous classical } \\
\text { section scar }\end{array}$ & s & 5.88 \\
\hline $\begin{array}{l}\text { Previous lower } \\
\text { segment scar }\end{array}$ & 32 & 94.12 \\
\hline Total & 34 & 100 \\
\hline
\end{tabular}

It is evident from the above table that the most of cases of previous caesarean section scar rupture during labour was lower segment caesarean section scar $(94.11 \%)$ (Table 5).

Table 6: Causes of traumatic rupture.

\begin{tabular}{|lll|}
\hline $\begin{array}{l}\text { Causes of traumatic } \\
\text { rupture }\end{array}$ & $\begin{array}{l}\text { No of cases of } \\
\text { rupture uterus }\end{array}$ & Percentage \\
\hline $\begin{array}{l}\text { Difficult ventous } \\
\text { delivery (outside Rims) }\end{array}$ & 1 & 25 \\
\hline $\begin{array}{l}\text { Injudicious use of } \\
\text { Oxytocics }\end{array}$ & 3 & 75 \\
\hline Total & 4 & 100 \\
\hline
\end{tabular}

It was observed from the above table that traumatic rupture now a day is becoming rare. The most common cause of traumatic rupture was injudicious use of oxytocins $(75 \%)$ (Table 6$)$.

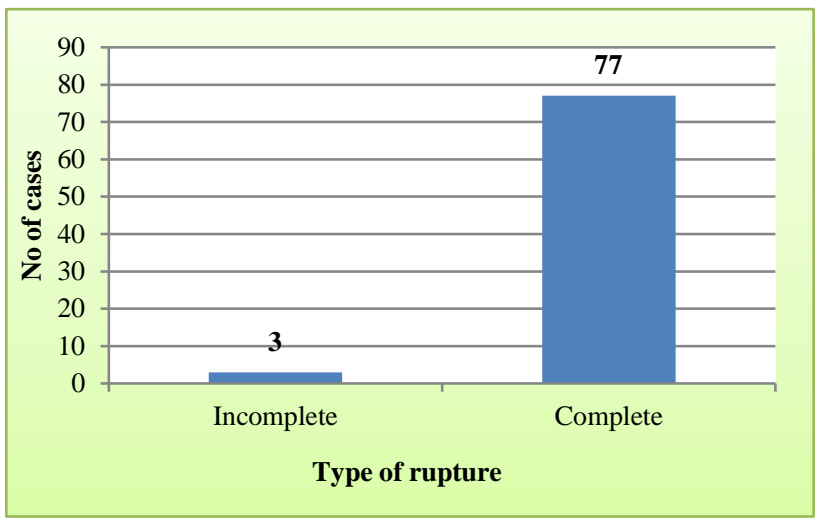

Figure 2: Distribution of cases according to type of rupture.

It is evident from the above table that majority of cases of rupture uterus were of complete type (96.25\%) (Figure 2).

It is apparent from the above table that the most frequent site of rupture was in the anterior wall of lower segment in $68.75 \%$ of cases.

Left lateral tear of lower segment was more common $(26.25 \%)$ than right lateral tear of lower segment (12.5\%). In $11.25 \%$ of cases posterior wall was involved. In $10 \%$ of cases left lateral wall and in $6.25 \%$ cases right lateral wall were involved (Figure 3).

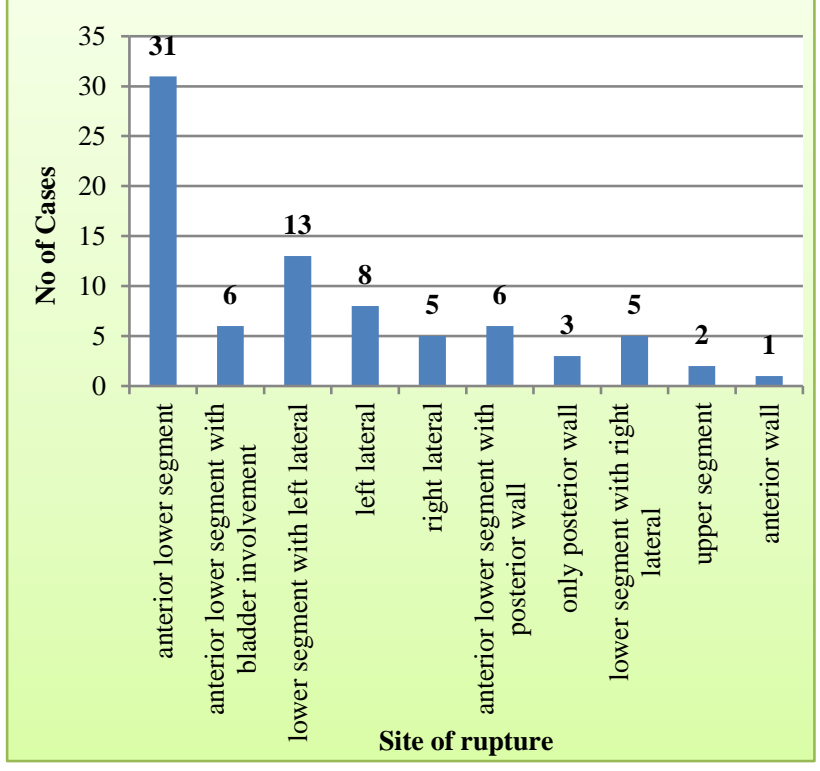

Figure 3: Distribution of cases according to the site of rupture as seen during laparotomy.

In present observation, it was noted that the absent foetal heart sounds was the commonest feature involved in 78 cases out of 80. Two patients with present foetal heart sounds had live babies and were the cases where a caesarean section was decided upon and on commencing incomplete rupture of the uterus was found at operation.

Palpation of superficial foetal parts was feature in 74 cases, uterine contour was lost in 74 cases and cessation of uterine contraction was elicited in 75 cases. Abdominal tenderness was observed in 56 cases. Haematuria was seen in 40 cases. Vaginal bleeding was a feature in 19 cases in the present series and was not seen when the presenting part was impacted (Table 7).

Table 7: Clinical feature in cases of rupture uterus.

\begin{tabular}{|l|l|}
\hline Clinical feature & No. of cases \\
\hline General condition & 70 \\
\hline Pallor & 10 \\
\hline Dehydration & 15 \\
\hline Tachycardia & 10 \\
\hline Hypotension & 08 \\
\hline Cold clammy skin & \\
\hline Per abdominal examination & 20 \\
\hline Abdominal distension & 15 \\
\hline Distended bowel loop & 78 \\
\hline Absent foetal heart sound & 74 \\
\hline Palpation of superficial foetal parts & 74 \\
\hline Loss of uterine contour & 75 \\
\hline Cessation of uterine contraction & 56 \\
\hline Abdominal tenderness & 19 \\
\hline Vaginal bleeding & 40 \\
\hline Haematuria & 10 \\
\hline Oliguria & \\
\hline
\end{tabular}


Table 8: Surgical management in cases of rupture uterus.

\begin{tabular}{|lll|}
\hline Type of Surgery & No. of cases & $\%$ \\
\hline Hysterectomy & 43 & 53.75 \\
\hline Subtotal & 32 & 40 \\
\hline With bladder repair & 05 & 6.25 \\
\hline $\begin{array}{l}\text { Without bladder repair } \\
\text { Repair of rupture }\end{array}$ & 27 & 33.75 \\
\hline $\begin{array}{l}\text { With bilateral tubectomy } \\
\text { With bilateral tubectomy and } \\
\text { bladder repair }\end{array}$ & 24 & 30 \\
\hline Repair of tear & 1 & 1.25 \\
\hline Total & 80 & 15 \\
\hline
\end{tabular}

It is apparent from the Table 8 that in majority of cases $(53.75 \%)$ hysterectomy was done, as these cases showed ragged tears and were badly infected. In 25 cases, repair with ligation was done. In 12 cases conservative approach with repair of tear was only done. In 6 cases, there was involvement of bladder also; bladder repair was done along with hysterectomy (Table 8).

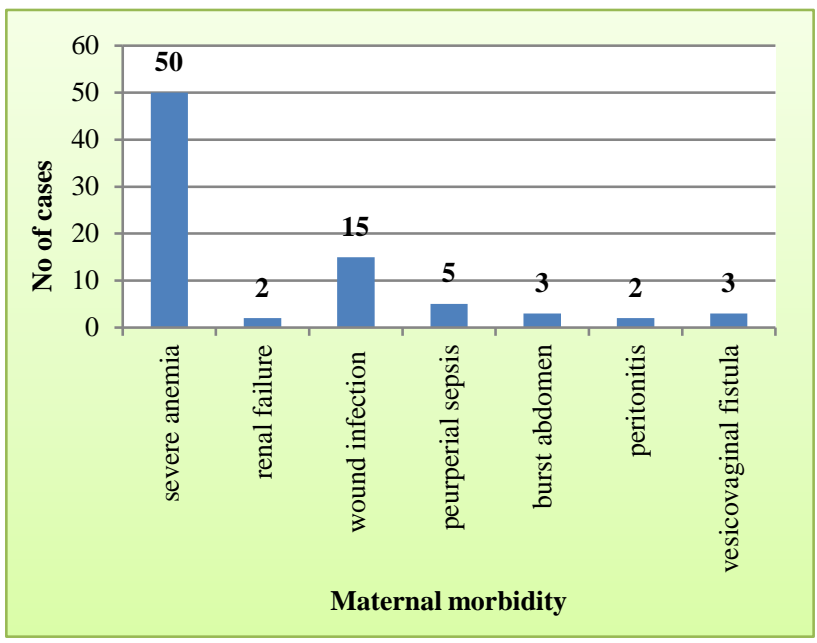

Figure 4: Causes of maternal morbidity in cases of rupture uterus.

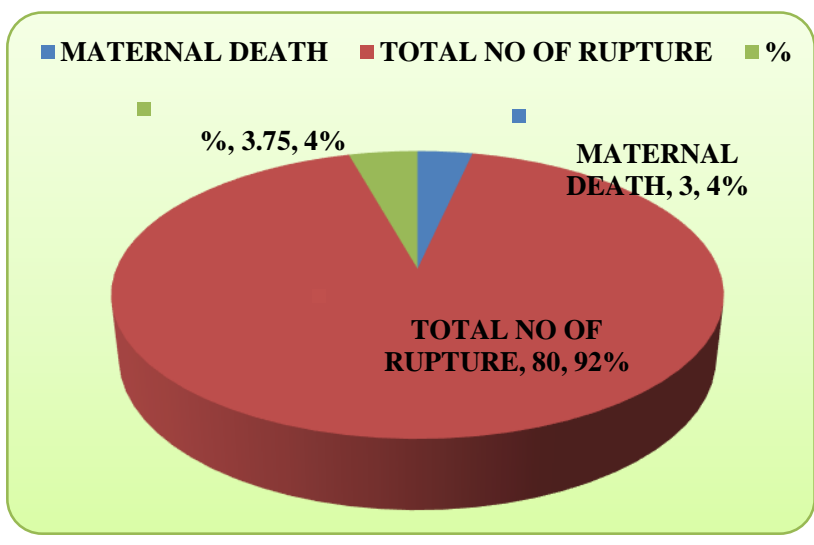

Figure 5: Incidence of maternal mortality in cases of rupture uterus.
Major cause of morbidity was severe anaemia due to unavailability of blood bank services in the rural areas $(62.5 \%)$. Variable degrees of wound infection were noted in 15 cases with burst abdomen in 3 cases. 3 cases $(3.75 \%)$ developed vesicovaginal fistula (Figure 4).

It is evident from the Figure 5 that the maternal mortality rate in cases of rupture uterus was $3.75 \%$.

Table 9: Incidence of perinatal mortality in cases of rupture uterus.

\begin{tabular}{|lll|}
\hline Time of foetal death & Total no. of cases & $\%$ \\
\hline Still Birth & 78 & 97.5 \\
\hline Live Birth & 2 & 2.5 \\
\hline Total & 80 & 100 \\
\hline
\end{tabular}

It is observed from the above table that perinatal mortality in cases of rupture uterus was very high $(97.5 \%)$ (Table 9).

\section{DISCUSSION}

Total number of deliveries at R.I.M.S, Ranchi during March 2014 to September 2015 was 10474. Total number of rupture uterus during same period was 80 . The incidence of rupture uterus was 0.763. Incidence of rupture uterus varies greatly according to centre to centre where cases have been being reported.

In developed countries rupture uterus is practically a complication greater to previous caesarean scar and it has been reported to be $0.8 \%$ in previous low transverse scar and $4.8 \%$ with previous classical scar (Gupta A et al). ${ }^{15}$

Table 10: Incidence of rupture uterus in others and present study.

\begin{tabular}{|c|c|c|}
\hline Author and Year & City/Country & Incidence \\
\hline Naik et al ${ }^{16}$ & India & $0.4 \%$ \\
\hline Chhabra $\mathrm{S}$ et al ${ }^{17}$ & India & $0.06 \%$ \\
\hline Dutta et $\mathrm{al}^{18}$ & India & $0.05-0.5 \%$ \\
\hline Singh $A^{19}$ & India & $0.3 \%$ \\
\hline Amanael $\mathrm{G}$ et $\mathrm{al}^{20}$ & Ethiopia & $0.9 \%$ \\
\hline Khan $S$ et $\mathrm{al}^{21}$ & Pakistan & $1 \%$ \\
\hline Odusoga OL et $\mathrm{al}^{22}$ & Nigeria & $1.49 \%$ \\
\hline Ezegwui $\mathrm{A}$ et $\mathrm{al}^{23}$ & Nigeria & $0.9 \%$ \\
\hline Present study & India & $0.7 \%$ \\
\hline
\end{tabular}

It has been observed that there is gradual decline in incidence of rupture uterus. This improvement is due to gradual development of health care in rural areas, increased awareness for promotion of institutional deliveries and more specialized services at the peripheral hospital.

In present study including 80 cases of rupture uterus, the incidence of unbooked cases was $97.5 \%$ (78 cases) and that of booked was $2.5 \%$. Present finding is similar to that 
of Chaubey MK, India in 1986 who also reported $97.5 \%$ incidence of rupture uterus among unbooked cases. In these unbooked cases presenting with rupture uterus coming from rural areas had no or irregular antenatal check-up, some of these were grand multipara and there was a long gap between the onset of labour and hospitalization.

In present study Table 2 shows out of 74 patients coming from rural background the incidence of rupture uterus was $92.5 \%$ and that of 6 patients from urban background was $7.5 \%$. Illiteracy, poor transport, no antenatal checkup, social customs and prior successful home deliveries prevent these ladies from seeking medical advice and they come to hospital only when some unavoidable complication has taken place and that too very late.

In this study, Table 2 shows distribution of age 34 ladies between the age group 21-25 years had maximum number of incidence of rupture uterus that is $42.5 \%$, followed by age group 26-30 years showed 37.5\% (30 cases). Shastrakar reported maximum incidence of rupture uterus in age group 16-20 years followed by age group 21-35 year. ${ }^{24}$ Khattak $\mathrm{Z}$ et al found majority of the patient were of age group 31-40 year followed by 21-30 years. ${ }^{25}$ Latika $S$ et al found maximum number of rupture uterus between age group 21-30 years. ${ }^{26}$ Omole-Ohonsi A et al also found most of the rupture occurred between 2130 years. ${ }^{27}$ Present study appears similar to Latika ${ }^{26}$ and Omole et al. ${ }^{27}$

In present study the incidence of rupture was high in para 2 and 3 and it may be due to more number of cases being of para 2 and 3 (51 cases $=63.75 \%$ ) compared to grand multiparus that is only $6(7.5 \%)$. Present findings are similar to Singh A et al, who also reported maximum number of rupture uterus in parous lady was 92\% (37 cases) and 3 cases of rupture was seen in primigravida $(3.75 \%) .{ }^{19}$ Eden et al had also reported maximum number of cases i.e. $83.3 \%$ in multiparous women. ${ }^{28}$

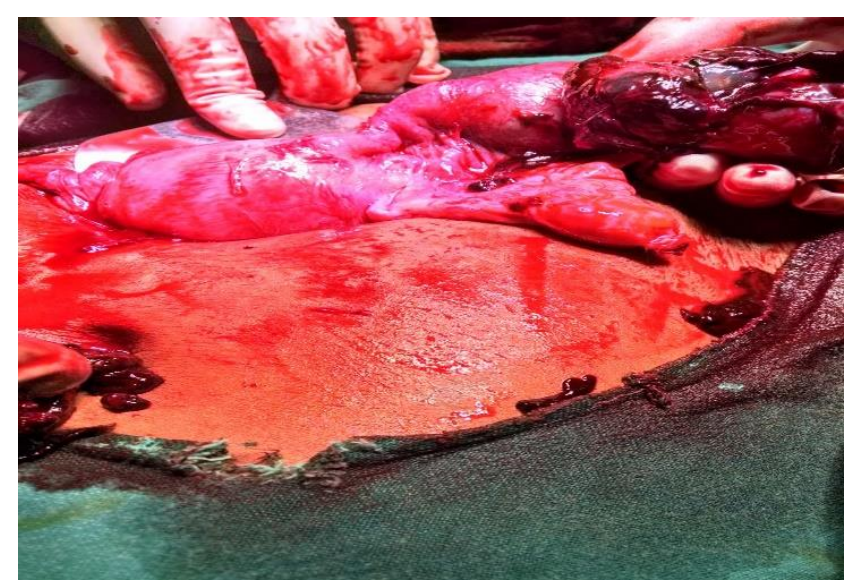

Figure 6: Cornual rupture.

Visariya $\mathrm{N}$ et al also reported $1^{\text {st }}$ trimester spontaneous rupture of LSCS scar so LSCS scar rupture can occur throughout the pregnancy, maybe due to weak scar. ${ }^{29}$ Women having caesarean delivery should be advised not to conceive within months of delivery. Guise JM et al reported $3 \%$ rupture of myomectomy scar during subsequent pregnancy. ${ }^{30}$ In present study no case with previous myomectomy scar rupture was present. Uterine rupture in labor may be in unscarred uterus, traumatic or due to dehiscence of the scar. In this observation, spontaneous rupture in unscarred uterus was the commonest type, forming $49.34 \%$ (37 cases) of rupture. Naik B, Amanael $G$, Khan $S$ et al also observed that spontaneous rupture was the commonest type forming $46-70 \%$ of rupture, studied by them. ${ }^{16,20,21}$

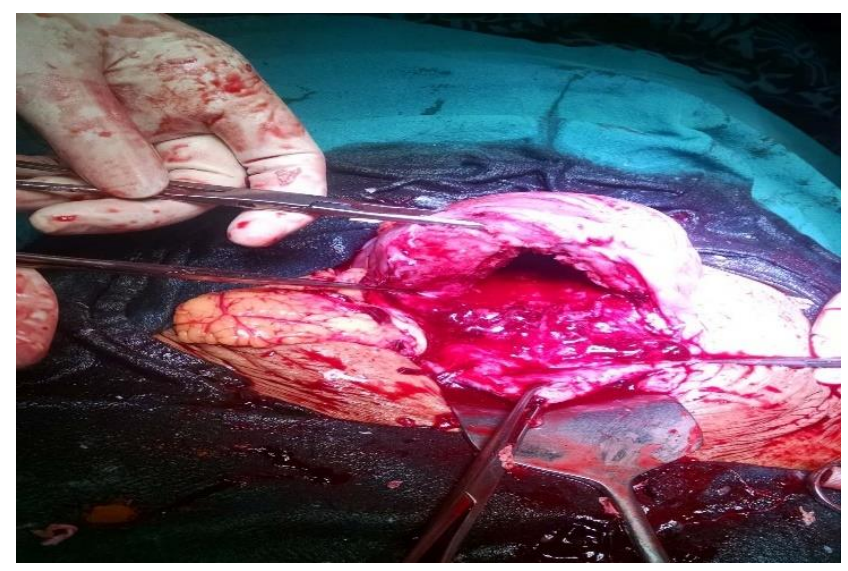

Figure 7: Lower segment scar rupture.

The incidence of scar rupture in present study was found to be $45.33 \%$ (34 cases). This observation was similar with the observation of Choubey MK et al and Ofir K et al. ${ }^{21,31}$ Traumatic rupture of the uterus is becoming rare, 4 cases of traumatic rupture occurred in my study giving an incidence of $5.33 \%$. Out of 3 cases where probably due to misuse of oxytocin, methergin by untrained person. These patients come with rupture uterus and gave history of being attended at periphery and use of I.V fluids and drugs followed by cessation of labour pain and detoriation of condition.

This study was comparable with Khan $\mathrm{S}$ et al he demonstrated the major cause of traumatic rupture as injudicious use of oxytocin by untrained dais, lack of proper protocol for the use of oxytocin coupled with poor monitoring of labor in the rural areas. ${ }^{21}$ These were is the contributing factors to the occurance of rupture uterus among the induced group. Spontaneous rupture was common in my study because many patients with obvious risk factors attempted labour at home and therefore came to hospital late. Out of these only $2.5 \%$ had antenatal checkup.

In the present study, the type of caesarean scar ruptured during labour was mostly lower segment caesarean section scar (94.11\%). Despite the chances of rupture being common in previous classical scar we found more in lower segment scar. This can be explained because 
only 2 cases of previous upper segment scar rupture were present during labour in present study. Khan $\mathrm{S}$ et al also said in his study the decrease in the use of high forcep and internal podalic version and breech extraction and the more frequent use of caesarean section in malpresentation and malposition, have decreased the frequency of traumatic deliveries and the relative incidence of this type of rupture. $^{21}$

During the present study there were $77(96.25 \%)$ cases of complete rupture and the remaining $3(3.75 \%)$ were of incomplete type. Ahmed SM observed 76 complete rupture and 10 incomplete ruptures. ${ }^{32}$ Admassu A observed 62 complete rupture and 8 incomplete ruptures. $^{33}$

In present study most, common site of rupture was anterior lower segment i.e. $68.5 \%$. Next most common site was left lateral rupture $(26.25 \%, 21 / 80)$, followed by right lateral $(12.5 \%, 10 / 80)$, followed by fundal rupture $(10 \%, 8 / 80)$ respectively. There were 6 cases $(7.5 \%)$ with bladder rupture and all had rupture at the lower segment, although majority had hematuria. Begum $\mathrm{S}$ et al studying the cases of rupture uterus found 16 cases of transverse rupture through anterior wall of lower uterine segment $(16 / 34,47 \%) .{ }^{34}$ This was the most common site of rupture uterus. Next most common site was left lateral rupture $(8 / 34,23.5 \%)$ followed by fundus rupture $(7 / 34,20.6 \%)$ and right lateral rupture $(3 / 34,8.8 \%)$ respectively.

It was noted that absent fetal heart sound was the commonest feature in 78 out of 80 cases. In present study fetal heart sound was present in 2 cases with fetal distress and during caesarean section partial rupture of the uterus was found. Gardeil F during an analysis of 26 cases of rupture of scar observed that 16 cases were of incomplete uterine rupture with the fetus still in utero and varying degree of separation of scar present. ${ }^{35}$ Ibha K et al noticed that clinical feature were extremely variable and most of the women presented with more than one feature. ${ }^{36}$

Out of 80 cases of rupture uterus, Hysterectomy was performed in 43 cases. Subtotal hysterectomy was done in 32 cases i.e. $40 \%$. Total hysterectomy was done in 11 cases i.e. $13.5 \%$. Out of these bladder repair was done in 6 cases. Repair of rent was done only in 12 cases i.e. $15 \%$ and repair of rent and bilateral tubectomy was done in 25 cases i.e. $31.25 \%$. Habiba $U$ et al reported that hysterectomy either total or subtotal was performed in $70 \%$ of their cases of rupture uterus. ${ }^{37}$

In the present series, there are 3 maternal deaths out of 80 cases of ruptured uterus giving the maternal mortality rate of $3.75 \%$. These resulted from hemorrhagic shock in 2 cases and septicemia in 1 case. The mortality rate was similar to that found by Mokgokong, who noted that the maternal mortality rate associated with uterine rupture largely depends on whether the diagnosis is established before or after delivery. ${ }^{38}$ In the study done by Singh A et al the maternal mortality rate was $2.5 \% .{ }^{19}$ It was observed that out of 80 babies, 78 were lost giving the perinatal mortality rate of $(97.5 \%)$. The present incidence of perinatal mortality was in close to the reports of Khan S et al and Malik HS. ${ }^{21,39}$

The limitation of this study is that it shows details of rupture uterus pertaining to a specific geographic area in Ranchi and cannot be extrapolated to the Indian population as a whole. Also, our hospital being a tertiary centre, receives many referral cases from adjacent areas so the incidence of rupture is likely to be higher.

\section{CONCLUSION}

The present study was carried out in 80 cases of rupture uterus admitted in labour room in the department of Obstetrics and Gynaecology, RIMS, Ranchi from March 2014 to September 2015. About 80 cases of rupture uterus were managed during the period of March 2014 to September 2015. There were 80 cases of rupture uterus among the total 10,474 deliveries at RIMS labour room giving an incidence of $0.763 \%$. Out of 80 patients of rupture uterus only $2.5 \%$ of cases had antenatal check- up that to infrequent, rest $97.5 \%$ were un-booked and had came directly to the labour room as emergency cases. The incidence of rupture uterus was more $(92.5 \%)$ in rural population than urban $(7.5 \%)$. About $70 \%$ patients presenting with feature of rupture uterus were from the low socioeconomic group. Approx $42.5 \%$ cases were in the age group of $21-25$ years and $37.5 \%$ were in the age group of 26-30 years, $12.5 \%$ cases in the age group of 3135 and $2.5 \%$ in the age group of 36 year and above. $63.75 \%$ of cases were of para 2 and $3,25 \%$ were para 4 and $5,7.5 \%$ were grand multipara and $3.75 \%$ were primigravida. About $53.75 \%$ of ruptures of uterus were noted after 38 weeks of pregnancy. Cases of rupture uterus were noted mainly after 30 weeks of pregnancy and during labour but there was one case of previous caesarean scar rupture at 16 weeks of pregnancy, 2 cases of congenital malformed uterus had ruptured at 30 and 32 weeks of pregnancy. $93.75 \%$ of rupture of uterus occurred during labour and $6.25 \%$ during pregnancy. Among the 5 cases of ruptured uterus during pregnancy, 3 cases were of previous LSCS scar rupture and 2 cases of spontaneous rupture during pregnancy due to congenital malformed uterus. The cause of rupture uterus during labour in most of the cases was spontaneous $(49.34 \%)$. scar rupture was the next frequent cause $(45.33 \%)$ and traumatic rupture were $5.33 \%$. Malpresentation and malposition contributed the most important aetiological factors causing spontaneous rupture during labour (43.24\%). Among these malpresentation occipitoposterior presentation was found to be the commonest $21.62 \%$. The type of caesarian section scar ruptured during labour was mostly lower segment caesarian section scar $(94.11 \%)$. There were only 2 cases $(5.88 \%)$ of previous classical caesarian section scar and both ruptured during labour. 
Hysterectomy was performed in $53.75 \%$ (subtotal, 32 cases i.e. $40 \%$ and total, 11 cases i.e. $13.75 \%$ ). The rest was repaired in $15 \%$ and the tubectomy was done along with repair of tear in $30 \%$. Associated bladder tear were repaired along with hysterectomy in $6.25 \%$ of cases. Hysterectomy was the treatment of choice depending upon the number of living children, condition of patient, site and extent of rupture and sepsis. Maternal mortality was in 3 cases $(3.75 \%)$ and all 3 died in post op period. About 2 patients died at $48 \mathrm{hr}$ and 1 patient died at $72 \mathrm{hr}$ post operatively. Shock and hemorrhage and anemia were the commonest cause of maternal mortality.

Limited resources and health care centers in remote areas, lack of awareness and education regarding regular antenatal checkups, delay in diagnosing cases (prolonged and obstructed labour) and referring to higher centers, time lost in travel were the major hurdles that we identified in present study.

\section{Funding: No funding sources}

Conflict of interest: None declared

Ethical approval: The study was approved by the Institutional Ethics Committee

\section{REFERENCES}

1. Miller DA. Intrapartum rupture of unscarred uterus. Obstet Gynaecol. 1997;89:671-3.

2. Flamm BL. Once a caesarean, always a controversy. Obstet Gynaecol. 1997;90:312-5.

3. ACOG practice bulletin. Vaginal birth after previous caesarean delivery. No. 5, July 1999 (replaces practice bulletin no.2, October 1998). Clinical management guidelines for obstetricians and gynaecologists. Int J Gynaecol Obstet. 1999;66:197204.

4. Konje JC, Odukoyo OA, Lapido OA. Uterine rupture in Ibadan: A twelve year review. Gynecol Obstet. 1990;32:207-213.

5. Padhye SM. Rupture of pregnant uterus- a 20 years review. Kathmandu University Med J. 2005;3:234-8.

6. Flamm BL, Anton D, Goings JR, Newman J. Prostaglandin E2 for cervical ripening: a multicentre study of patients with prior caesarean delivery. Am J Perinatol. 1997;14:157-60.

7. Eden RD, Parker RT, Gall SA. Rupture of the pregnant uterus: a 53 year review. Obstet Gynecol. 1986;68:671-4.

8. Rahman J, Al-Sibai MH, Rahman MS. Rupture of the uterus in the labour. A review of 96 cases. Acta Obstet Gynecol Scand.1985;64:311-5.

9. Leung AS, Leung EK, Paul RH. Uterine rupture after previous caesarean delivery: maternal and fetal consequences. AM J Obstet Gynecol. 1993;169:94550 .

10. Fedorkow DM, Nimrod CA, Tailor PJ. Ruptured uterus in pregnancy: A Canadian Hospital experience. Can Med Assoc. 1987;137:27-31.
11. Blanchette $\mathrm{H}$, Blanchette $\mathrm{M}, \mathrm{McCabe} \mathrm{J}$, Vincent $\mathrm{S}$. Is vaginal birth after caesarean safe? Experience at a community hospital. AM J Gynecol. 2001;184:147887.

12. Yap OW, Kim ES, Laros RK Jr. Maternal and neonatal outcomes after uterine rupture in labour. AM J Obstet Gynecol. 2001;184:1576-81.

13. Soltan MH, Khashoggi T, Adelusi B. Pregnancy following rupture of the pregnant uterus. Int $\mathbf{J}$ Gynecol Obstet. 1996;52:37-42.

14. Amanel G, Mengiste MM. Ruptured uterus- eight years retrospective analysis of the causes and management outcomes at Digrat Hospital Ethiopia. Ethiop J Health Dev. 2002;16:241-5.

15. Gupta A, Nanda S. Uterine rupture in pregnancy: a five-year study. Arch Gynecol Obstet. 2011 Mar; 283(3):437-41.

16. Naik B, Gohil JT, Pagi SL. Rupture uterus: A 12 years review. J Obstet Gynaecol India. 1996 Jun;46(3):334-40.

17. Chhabra S, Bhagwat N, Chakravorty A. Reduction in the occurrence of uterine rupture in Central India. J Obstet Gynaecol. 2002;22(1):39-42.

18. Datta S, Minocha S. How much misoprostol is safe? First reported case of second-trimester uterine rupture after a single low dose. J Obstet Gynaecol. 2016;36(4):549-51.

19. Singh A, Shrivastava C. Uterine Rupture: Still a Harsh Reality! J Obstet Gynaecol India. 2015;65(3):158-161.

20. Amanael G, Mengiste MM. Ruptured uterus-eight year retrospective analysis of causes and management outcome in Adigrat Hospital, Tigray Region, Ethiopia. J Health Dev. 2002;16:241-5.

21. Khan S, Parveen Z, Begum S, Alam I. Uterine rupture: a review of 34 cases at Ayub Teaching Hospital Abbottabad. JAMC. 2003;15(4):50-2.

22. Igwegbe AO, Eleje GU, Udegbunam OI. Risk factors and perinatal outcome of uterine rupture in a lowresource setting. Nigerian Med J: J Nigeria Med Assoc. 2013;54(6):415-9.

23. Ezegwui HU, Nwogu-Ikojo EE. Trends in uterine rupture in Enugu, Nigeria. J Obstet Gynaecol. 2005 Apr;25(3):260-2.

24. Shastrakar VD. Trends in uterine rupture. J Obstet Gynaecol India. 1962;12:391

25. Ummi H, Zaibunnisa K, Manzoor A. A review of 66 cases of rupture uterus in a district general hospital. JPMI. 2002;16(1):49-54.

26. Latika SA. A 10-year analysis of uterine rupture at a teaching institution. $\mathrm{J}$ Obstet Gynecol India. 2006;56:502-6.

27. Omole-Ohonsi A, Attah R. Risk factors for ruptured uterus in a developing country. Gynecol Obstetric. 2011;21:102.

28. Eden RD, Parker RT, Gall SA. Rupture of the pregnant uterus: a 53-year review. Obstet Gynecol. 1986;68(5):671-4

29. Visariya N, Purandare $\mathrm{CN}$, Bandukwalla V, Purandare N. First trimester uterine rupture previous 
lower segment cesarean scar. J Obstet Gynaecol India. 2011;61(1):88-9.

30. Guise JM, McDonagh MS, Osterweil P. Systematic review of the incidence and consequences of uterine rupture in women with previous caesarean section. BMJ. 2004;329:19.

31. Ofir K, Sheiner E, Levy A. Uterine rupture: Risk factors and pregnancy outcome. Am J Obstet Gynecol. 2003;189:1042-6.

32. Ahmed SM, Daffalla SE. Incidence of uterine rupture in teaching hospital, Sudan. Saudi Med J. 2001;22:757-61.

33. Admassu A. Analysis of Ruptured Uterus in Debre Markos Hospital, Ethiopia. East Afri Med J. 2004;81(1):52-5.

34. Begum S, Aziz-un-Nisa, Begum I. Analysis of maternal mortality in tertiary care hospital to determine causes and preventive factors. J Ayub Med Coll Abbottabad. 2003;15:49-52.

35. Gardeil F, Daly S, Turner MJ. Uterine rupture in pregnancy reviewed. Eur J Obstet Gynecol Reprod Biol.1994;56:107-10.
36. Kumari I, Goel P, Shegal A, Devi K. Rupture of gravid uterus: Experience at an urban medical centre in Northern India. $\mathrm{J}$ Obstet Gynecol India. 2003;6(53):558-62.

37. Habiba U, Khattak Z, Ali M. a review of 66 cases of ruptured uterus in a district general hospital. J Postgrad Med Inst. 2002;16:49-54.

38. Mokgokong ET, Marivate M. Treatment of the ruptured uterus. S Afr Med J. 1976;50(41):1621-4.

39. Malik HS. Frequency, predisposing factors and fetomaternal outcome in uterine rupture. J Coll Physicians Surg Pak. 2006;16:472-5.

Cite this article as: Beck R, Minj SD, Tirkey S, Kumar A, Sen S. Study the cases of rupture uterus in a tertiary care teaching hospital, Jharkhand, India and its maternal and perinatal outcome. Int J Reprod Contracept Obstet Gynecol 2018;7:938-46. 